\title{
Traditional medicines and alternative practice in the management of prostate dis- eases in southern Ghana
}

\author{
Mathew Y. Kyei ${ }^{1}$, George O. Klufio ${ }^{1}$, Ali Ayamba ${ }^{2}$ and Sherif Mohammed ${ }^{1}$ \\ Ghana Med J 2017; 51(3): 128-137 DOI: http://dx.doi.org/10.4314/gmj.v51i3.6
}

${ }^{1}$ Department of Surgery, School of Medicine and Dentistry, College of Health Sciences, University of Ghana, P. O. Box 4236, Accra, Ghana, ${ }^{2}$ The University of Health and Allied Health Sciences, PMB 31, Ho, Volta Region, Ghana

Corresponding author: Dr. M.Y. Kyei

E-mail: matkyei@yahoo.com

Conflict of interest: None declared

\section{SUMMARY}

Objective: This study was aimed at identifying Ghanaian traditional medicines used for the management of prostate diseases and their constituents. Reviews of studies conducted on them are also presented.

Methodology: This was a prospective study. Traditional Medicine samples from consecutive patients with either lower urinary symptoms (LUTS) presenting at the Urology Unit of the Korle Bu Teaching Hospital (KBTH) in Accra from January 2015 to June 2016 and had a prior treatment with traditional medicines, had the samples retrieved. Additionally, all the 58 licensed pharmaceutical shops in Okaishie, a whole sale and retail depot for medicines in the main business district of Accra, were visited and traditional medicines for the management of prostate diseases acquired. The products constituent as labeled were documented and entered once on a proforma. This study was part of a study on the management of benign prostate hyperplasia at the KBTH approved by the Medical Directorate.

The findings were analyzed and presented using descriptive statistics and presented as a table.

Results: Eleven products were identified with the main indigenous medicinal plant identified being the root extract of Croton membranaceus. This was the constituent in four products (Uro $500^{\circledR}$, UR-Quick mixture ${ }^{\circledR}$, Prostacure ${ }^{\circledR}$ and prostat $\left.{ }^{\circ} 60\right)$. Although studies on the basic pharmacology and animal studies have confirmed its effect on the prostate, only one clinical study was identified.

Conclusion: Croton membranaceus was the indigenous traditional medicine identified for relieving LUTS due to prostate disease. There is the need for empirical evidence on its efficacy in treating Prostate cancer.

Funding: Not declared

Keywords: Benign prostate hyperplasia, Prostate cancer, traditional medicine, Croton membranaceus

\section{INTRODUCTION}

Prostate diseases are common urological problems encountered by men in Ghana. The prevalence of moderate to severe lower urinary symptoms due to benign prostate hyperplasia among the Ghanaian population (aged between 50 and 74 years) has been found to be $19.9 \%^{1}$ and prostate cancer prevalence of $7 \%$ among men between 50 and 74 years. ${ }^{2,3}$

There are various indigenous terms used to describe the condition when complicated by inability to void or acute retention of urine. Among the Gas in the southern coastal areas of Ghana this condition is referred to as 'Shamo baa' which translated into English means, 'the urine is not flowing'. Other tribes have different expressions for inability to void due to prostate disease. In orthodox medical practice, various medications such as alpha-adrenergic blockers and 5 alpha-reductase inhibitors have been used successfully to manage the lower urinary tract symptoms associated with prostate hyperplasia.

In addition to refractory retention of urine (repeated urine retention) other complications from benign prostate hyperplasia such as haematuria, recurrent urinary tract infections, bladder calculi and renal insufficiency are managed with surgical interventions such as open prostatectomy and transurethral resection of the prostate. ${ }^{4}$ For the management of prostate cancer, patients who present early with local disease (cancer that had not spread) are offered either radical prostatectomy ${ }^{5,6}$ or radiation therapy (either as brachytherapy or external beam radiation therapy). 


\section{Original Article}

Anti-androgens such as flutamide or bicalutamide, synthetic oestrogens (diethylstilboesterol) and luteinizing hormone releasing hormone (LHRH) agonist are used to manage patients presenting with locally advanced or metastatic disease. ${ }^{6}$

For patients who cannot afford these agents, bilateral total orchidectomy is used even though most Ghanaian patients find it culturally unacceptable. For patients with locally advanced disease a combination of luteinizing hormone releasing hormone (LHRH) agonists and external beam radiotherapy is an alternate treatment regime.${ }^{6}$ Currently in Ghana, alternate medicine has been incorporated into the main stream medical services. As a result, more patients are resorting to Traditional Medicine to address their ailments including prostate conditions.

Other reasons for the increase in herbal medicine use in underdeveloped countries has been attributed to such factors as the high cost of pharmaceutical medicines and overcrowding of patients in clinics and hospitals. ${ }^{7}$ A study found that low-income levels, being a trader, perceiving traditional medicines as effective and safe, good affective behavior of traditional medicinal practitioner and having chronic ill health as predictors of utilization of traditional medicines among Ghanaians. ${ }^{8}$

Herbal medicine, botanical medicine or phytomedicine refers to using plant components such as seeds, berries, roots, leaves, bark, or flowers for medicinal purposes. It has been noted that Traditional Medical practice has long been used outside of conventional medicine but mainly for primary health care.

However, its use in Ghana has been extended to involve more tertiary conditions such as prostatism due to benign prostate hyperplasia (BPH) and prostate cancer. ${ }^{10}$ Phytotherapeutic agents have been noted to have attracted tremendous attention for the treatment of BPH and prostate cancer, because they are thought to be safer, more cost-effective, and have fewer side effects than conventional alternatives. ${ }^{11,12}$

Another reason for increased patronage has been attributed to improvements in analysis and quality control along with quality clinical research supporting the value of herbal medicine in the treatment and prevention of diseases. The use of herbal medicine has been reported to be on the increase in many developing and industrialized countries. $^{13,14}$

The World Health Organization (WHO) estimates that four billion people (about 80 percent of the world population) use herbal medicine for some aspect of primary health care. ${ }^{15,16,17}$ In Ghana $75 \%$ of the population are said to depend on traditional herbal medicine for their healthcare. ${ }^{18,19}$ The WHO encourages developing countries to supplement their health programs with traditional herbal preparations provided they are proven to be non-toxic. ${ }^{20}$

The Center for Research into Plant Medicine (now Center for Plant Medicine Research CPMR) in Ghana was established in 1975 by the Government of Ghana in recognition of the pioneering work of Dr. Oku Ampofo, a Ghanaian allopathic medical practitioner. Its mandate was to identify and characterize Ghanaian herbs with medicinal properties to support their use in a more scientific and evidence-based manner.

Ghana has a rich biodiversity and rich tradition of plant medicine in various forms and has an enormous number of indigenous medicinal plants. Traditional medicines in Ghana range from individual one-product, home-made product, to family-size and occasionally large scale production where the products are distributed and sold in Chemical and Pharmacy shops in the country. ${ }^{8}$

As noted earlier, Ghana has a dual system of medical practice that recognizes both traditional and orthodox medical practices in law and promotes their coexistence. This is intended to allow access by the greatest number of citizens ${ }^{21}$, thus there is inclusion of some traditional medicinal products in Ghana's essential drug list.

This new development stems from the fact that Traditional Medicine services are often affordable and accessible to the vast rural population and therefore serve as a forerunner in the primary medical care of the population. The model of integrating traditional herbal practice into the mainstream health system was commenced in 2010 and was based on WHO recommendations and in line with country-specific studies and observations.

The Ministry of Health/ Ghana Health Service (MOH / GHS) initiated the policy on institutionalizing herbal medicine services on pilot bases. Allowing graduate traditional herbal practitioners from the tertiary institutions to practice side by side with their orthodox practitioners with the added advantage of each being able to make referral (either way) for further management as found appropriate.

The drugs used were procured from Central Medical Stores (CMS) and Center for Plant Medicine Research in Ghana based on a Ministry of Health medicinal list. 


\section{Original Article}

However, some of the products are pending registration with the Ghana Foods and Drugs Authority, the body mandated to certify all medications used in the country. In a review of this current initiative, it was observed that the acceptability of the integration of the herbal and orthodox systems was $94.4 \%$ among core hospital staff.

The stated reasons for acceptability included it boosting confidence in herbal medicines, streamlining traditional practice, reducing pressure on orthodox care/ practice and ensuring the use of only herbal medicines approved by the regulatory body (Food and Drugs Authority).

The clinical staff that found the integration unacceptable were concerned that the move will lead to a perception of endorsement of 'quack' herbal practitioners. ${ }^{22}$ In this era of evidence-based medicine, some of these health professionals find it difficult to accept historical and empirical evidence as the only necessary criterion for herbal medicine's efficacy.

Prostate diseases are common urological problems encountered by men in Ghana. In line with the current incorporation into the mainstream medical services of traditional medicines, more patients are resorting to Traditional Medicine to address their ailments. ${ }^{8}$ This includes prostate conditions.

In our experience some patients request to be offered an option of traditional medicine in the normal urology clinics for prostate diseases. (Personal communications) Knowledge of the currently available traditional medicines for the management of prostate disease will equip practicing Urologists and Medical practitioners to enable them to appropriately counsel patients on the use of these medications.

This study was aimed at identifying the Ghanaian traditional medicines used for the management of symptoms related to prostate diseases, the constituents of the herbal products that were indigenous and their pharmacology. Also considered are studies that have been conducted on these products both animal and clinical. Areas of concern in the use of these herbal products as well as areas needing further research are highlighted.

\section{METHODS}

This was a prospective study. Traditional Medicine samples from consecutive patients presenting at the Urology unit of the Korle Bu Teaching Hospital in Accra (a major referral center for Southern Ghana) from January 2015 to June 2016 who complained of either obstructive or irritative lower urinary tract symptoms or its associated complications and had a prior treatment with traditional medicines, and consented either by sign- ing or thumb printing a consent form depending on the educational status had the samples retrieved.

Once a product was identified and retrieved, that product was not retrieved again. Seven products were identified this way from 5 patients with age range of 54 to 73 years. Additionally, all the 58 licensed pharmaceutical shops in Okaishie drug stores lane, a wholesale and retail depot for medicines including traditional medicines in the main business district of Accra were visited. Those with stocks of traditional medicines for the management of prostate diseases had the medicines acquired. The products constituents as labeled were documented. Okaishie was chosen as it is a wholesale and retail depot for medicines including traditional medicines in the main business district of Accra.

The products identified were compared to the medicines retrieved from the patients in order to ensure that all available medicines had been accounted for. This was supplemented with the monitoring of radio broadcast advertisements on three popular radio stations in Accra, from Monday to Friday 7.00am to 12 noon each day from January 2016 to June 2016 in order to identify additional products. Each product was entered once in a proforma. The products constituent as labeled were documented.

This data was obtained as part of the clinical component of the Survey of Prostate Cancer in Accra with ethical clearance by the University of Ghana (Noguchi Memorial Institute for Medical research) ethical review board. Traditional medicines intended to be used for treatment of prostate diseases which did not have the constituents indicated on the labels were excluded from the study.

\section{Data Analysis}

The findings were analyzed and presented using descriptive statistics and presented as a table. The indigenous constituents identified formed the basis of a literature search using PubMed and Google scholar data bases. Additionally, visits were made to the CPMR at Mampong-Akwapim to determine studies, animal and clinical, that had been performed on some of these products.

\section{RESULTS}

A total of 11 products were identified that had the management of prostate diseases as their main indication however, 3 were excluded as the labels did not indicate their constituents. (Table 1).

Seronoa repens and Saw Palmetto which are some of the main stay in the phytotherapy for lower urinary tract symptoms due to $\mathrm{BPH}$ were the constituents of four of 


\section{Original Article}

the herbal preparations - Prostavite mixture ${ }^{\circledR}$, Prostate care herbal capsules ${ }^{\circledR}$, Prostate health ${ }^{\circledR}$ and Freemax prostate cure ${ }^{\circledR}$ which also contained nettle root.
These are not indigenous plants in Ghana but the constituents are imported for the formulations.

Table 1 Traditional medicines for management of prostate diseases and their constituents

\begin{tabular}{|c|c|c|c|c|c|c|c|}
\hline Serial & Trade name & Formulation/ & \multicolumn{5}{|c|}{ Constituents as per label } \\
\hline 1 & Uro $500^{\circledR}$ & Capsule & $\begin{array}{l}\text { Croton membra- } \\
\text { naceus }\end{array}$ & & & & \\
\hline 2 & $\begin{array}{l}\text { Prostavite mix- } \\
\text { ture }^{\circledR}\end{array}$ & Liquid & Barosma betulina & Serenoa repens & Silybum marianum & herbal extracts & \\
\hline 3 & $\begin{array}{l}\text { Prostate care } \\
\text { herbal capsules }{ }^{\circledR}\end{array}$ & Capsule & Saw palmetto & $\begin{array}{l}\text { small flowered } \\
\text { willow herb }\end{array}$ & stinging nettle & pau darco & Buchu \\
\hline 4 & Prostate health ${ }^{\circledR}$ & Capsule & Saw palmetto & pumpkin seed & & & \\
\hline 5 & $\begin{array}{l}\text { UR-Quick Mix- } \\
\text { ture }^{\circledR}\end{array}$ & Liquid & $\begin{array}{l}\text { Croton membra- } \\
\text { naceus }\end{array}$ & Antaeus Africana & Cnestis ferruginea & & \\
\hline 6 & Prostacure ${ }^{\circledR}$ & Liquid & $\begin{array}{l}\text { Croton membra- } \\
\text { naceus }\end{array}$ & & & & \\
\hline 7 & $\begin{array}{l}\text { Freemax prostate } \\
\text { cure }^{\circledR}\end{array}$ & Capsule & Seronoa serrulata & nettle root & & & \\
\hline 8 & Prostat $60^{\circledR}$ & Capsule & $\begin{array}{l}\text { Croton membra- } \\
\text { naceus }\end{array}$ & Anona muricata & & & \\
\hline
\end{tabular}

The main indigenous medicinal plant used for the management of prostate diseases in Ghana is the root extract of Croton membranaceus Mull. Arg. (Euphorbiaceae) [C. membranaceus], which was a constituent in four of the products. It has been observed to relieve symptoms of $\mathrm{BPH}$ and enhance urination without the accompanying difficulty. It is marketed as URO $500^{\circledR}$ with $10 \mathrm{mg}$ oral formulation of the plant by weight. The product is packaged by the CPMR. This plant was found in three other preparations (UR- Quick ${ }^{\circledR}$ Mixture, Prostacure ${ }^{\circledR}$ and Prostat $\left.60^{\circledR}\right)$.

\section{DISCUSSION}

The interest in the Ghanaian indigenous plant C. membranaceus in the management of prostate diseases (found in four of the products - Uro $500^{\circledR}$, Prostat $60^{\circledR}$, Uro-Quick $^{\circledR}$ mixture and Prostacure ${ }^{\circledR}$ ) has led to various laboratory studies to identify the active constituents. Both animals and human studies aimed at understanding the underlying mechanism of its action and its clinical effectiveness has been conducted.

Basic constituents/pharmacology of Croton membranaceus

A study by Aboagye FA showed that C.membranaceus inhibited the enzyme activity of $5 \alpha$-reductase in rat ${ }^{23}$ serum leading to a reduction in the levels of dihydrotes- tosterone levels in vitro however no significant reductions in the serum levels of dihydrotestosterone was observed in vivo.

This led him to conclude that inhibition of $5 \alpha$-reductase activity may not be the major mechanism by which the extract exerts its action on patients with LUTS due to $\mathrm{BPH}^{23}$ Thus the exact mechanism of action of the $\mathrm{C}$. membranaceus is yet to be established.

The compound Julocrotine, a glutarimide alkaloid has been isolated from the plant. ${ }^{24} \mathrm{~A}$ study by Baylor et al. identified a cytotoxic diterpenoid from C. membranaceus which was felt could underlie claims of its use for cancer treatment. ${ }^{25}$ A methanolic extract of the roots has also been shown to have cytotoxic activities against two cancer cell lines. ${ }^{26}$ A bioassay-guided fractionation of this extract revealed that the cytotoxic activity resided mostly in the ethyl acetate fraction. Six compounds were isolated from this fraction, including a furanoclerodane diterpenoid, for which the name crotomembranafuran was suggested. ${ }^{26}$ This compound exhibited an IC50 value of $4.1 \mu \mathrm{g} / \mathrm{mL}(10.6 \mu \mathrm{M})$ against human prostate cancer (PC-3) cells, which might provide some support for the traditional use of $C$. membranaceus in the treatment of cancers. ${ }^{26}$ 


\section{Original Article}

These findings are important as the use of the herbal medication for the treatment of prostate cancer considered a tertiary care disease is being practiced. However, it's clinical efficacy in treating prostate cancer is yet to be ascertained.

\section{Formulation of Croton membranaceus}

Various formulations of the root extract is available; ethanol extracts (liquid, tablets and capsules) and aqueous extracts (liquid). Bayor et al. demonstrated that the oral capsule was the most appropriate dosage form for C. membranaceus. In their study, they formulated both liquid and solid oral dosage forms from the ethanol extract of C. membranaceus ${ }^{27}$ root and investigated their physicochemical properties, release effects and suitability in comparison with aqueous decoctions and unformulated powdered plant material.

They observed that the ethanol extract had characteristics similar to the aqueous decoction, but unlike the later, it maintained its specifications and stability throughout the period of study. The use of large volumes, convenience and short shelf life, was said to limit the application of aqueous decoctions. The assessed properties of the prepared tablets and capsules met all the specifications required for good quality and had the advantage that it could be used in simple and convenient doses of one tablet or capsule, three times a day, in place of unstable decoctions and large volume solutions.

They also observed that the in vitro release profile of the capsules was however, better and significantly higher than that of the tablets. They concluded that oral capsules should be the preferred choice of solid dosage form for C. membranaceus and that its use will ensure compliance and maximize therapeutic outcomes. ${ }^{27}$ While Uro $500^{\circledR}$ and Prostat $60^{\circledR}$ were capsules, UroQuick ${ }^{\circledR}$ mixture and Prostacure ${ }^{\circledR}$ (powder)were administered as aqueous decoctions.

\section{Animal studies on Croton membranaceus}

Various animal studies have been performed on $C$. membranaceus. In a study by Afriyie et al on the treatment of BPH with C. membranaceus in an experimental animal model, they set out to evaluate if C. membranaceus root extract could attenuate the development of $\mathrm{BPH}$ in adult male Sprague-Dawley rats. ${ }^{28}$ Though they did not find statistical difference in prostate size in those receiving $C$. membranaceus root extract, there was attenuation of the growth of the stromal and epithelium cells. This finding was similar to the use of finasteride (a 5-alpha reductase inhibitor) in a comparable group with an associated shrinkage of the prostate. ${ }^{28}$ Noteworthy was lowering of the prostate specific antigen in the group.
As noted, an earlier study that sort to determine if $\mathrm{C}$. membranaceus led to reduction in dihydrotestosterone levels in rat serum, found it to inhibit the synthesis of dihydrotestosterone by prostatic $5 \alpha$-reductase in the rat in vitro, but did not confirm that C. membranaceus had significant effect in lowering dihydrotestosterone levels in vivo. ${ }^{23}$

Another study evaluated Mitochondria-dependent apoptogenic activity of aqueous root extract of $C$. membranaceus against human BPH-1 cells ${ }^{29}$ and found that $C$. membranaceus root extract induced a significant dosedependent inhibition in the proliferation of BPH-1 cells with significant DNA fragmentation, and the induction of mitochondria- dependent apoptosis of the BPH-1 cell lines. $^{29}$

\section{Clinical studies on use of Croton membranaceus}

Only one observational clinical study on the use of $C$. membranaceus on clinical $\mathrm{BPH}$ has been published to date. In a study of 33 patients presenting with lower urinary symptoms due to $\mathrm{BPH}$, but with 30 of them completing the study, Asare et al showed that a freezedried $C$. membranaceus ethanol root extract administered orally at a dose of $20 \mathrm{mg}$ eight hourly for 3 months led to an improvement in the international prostate symptoms score with a shift from severe lower urinary symptoms to moderate to mild symptoms. ${ }^{10}$

The tools used in this observational study were the International prostate symptoms score (IPSS), International index of erectile function and abdomino-pelvic ultrasound to determine prostate size and post void residual urine volume. The proportion of patients with severe symptoms reduced from $37 \%$ to $0 \%$ while the proportion with mild symptoms increased from $23 \%$ to $43 \%$. Those with moderate symptoms however increased from $40 \%$ to $57 \%$.

Thus, although there was improvement in those with severe symptoms there still remained a significant number of them with moderate symptoms (IPSS 9-19) which raises issue about the effectiveness of the C. membranaceus extract. Reduction in prostate size (shrinkage) was also observed in the study, with the mean prostate volume decreasing from 101.8 to 54.5 grams. This reduction in the glandular weight reflects a reduction in possible glandular components.

However, its effect on prostate smooth muscle activity (ie relaxation) was not accessed. Similarly, uroflow rate using an uroflowmeter as an objective means of establishing reduction in bladder outlet resistance was not accessed in this observational study. Also, prostate size determination was by way of an abdominopelvic ultra- 


\section{Original Article}

sound as against the use of transrectal ultrasound which has been noted to give a more accurate determination of prostate volume.

A large study with a relatively long duration of treatment and with the inclusion of uroflowmetry measurement is needed to ascertain the long-term efficacy of the C. membanaceus in clinical practice. Though there was derangement in liver function observed based on increases in total and indirect bilirubin as well as apolipoprotein they were not associated with clinical symptoms. ${ }^{10}$ Effect on these parameters with longer term use need to be examined.

C. membranaceus has been used as a traditional medicine for the treatment of prostate cancer. Animal studies have indicated its cytotoxic effect on BPH-1 cell lines as well as C. membranaceus promoting apoptosis. ${ }^{29}$ Another important observation is the associated reduction of the serum prostate specific antigen (PSA) both in animal studies ${ }^{28}$ and human clinical studies. ${ }^{10}$ Reduction in PSA level though observed in the use of 5-alpha reductase, is an important marker of the clinical effectiveness of anti-prostate cancer agent such as antiandrogens and luteinizing hormone releasing hormone agonist. This has led to a suggestion supporting its use as traditional medicine for the management of prostate cancer. $^{25}$

Despite these observations, no clinical studies have been conducted on the use of C. membranaceus in the management of prostate cancer either to achieve cure or to reduce its progression. Observations at urology clinics find that patients with prostate cancer on C. membranaceus present with advanced and metastatic disease despite having been on this traditional medicine treatment for considerable period of time.

\section{Toxicity/ Side effects and caution on use of Croton membranaceus}

Toxicity studies on C. membranaceus in animals identified no toxicity to the major organs of the body. ${ }^{30} \mathrm{Of}$ interest is an advantage of it being potentially antiatherogenic and anti-ischemic. ${ }^{31}$ No adverse biological effect has been noted in other studies. ${ }^{32,33}$ In the clinical study on its use in $\mathrm{BPH}$, there were no observable adverse effects associated with the clinical use of preparations of $C$. membranaceus during the study period of three months. However, the liver function tests had some parameters increasing slightly with a statistically significant increase in the total bilirubin and indirect bilirubin. $^{10}$
Pharmacovigilance must be heightened if these products are used in order to identify side effects not seen in the aforementioned studies which involve small numbers of subjects and a short duration of follow-up.

Variations in constituents of traditional herbal medicines have been of concern. It has been noted that the widespread disregard for quality control in the health food industry has brought into disrepute many important medicinal herbs. Herbal medicines, as they are now prepared in Ghana, contain varying levels of active constituents. Some medicines may have high levels of active constituents and thus lead to over- dose while others may have little or no active constituents at all, and may at best be described as placebos. ${ }^{8}$ Without proper quality control, there is no assurance that the herbal product contained in the bottle is the same as what is stated on the label. ${ }^{34}$ Standardization must therefore be pursued.

Bacteria contamination of products has also been of concern. In a study by Ampofo et $\mathrm{al}^{7}$, thirty-one herbal preparations produced from different processing companies and sold on the Ghanaian market were randomly purchased from sales outlets and analyzed for their microbiological quality by testing for the presence of total coliform bacteria, faecal coliform bacteria, and total heterotrophic bacteria count.

They also looked for pathogenic bacteria such as the Salmonella spp. and Clostridium spp as well as opportunistic bacterial pathogens (Aeromonas spp., Enterococcus spp. and Pseudomonas spp.) and mould. Of interest in the findings is the fact that herbal preparations tested included some indicated for treatment of urine retention.

After culturing aliquots of the various herbal products on various selective media, twenty-six (26) of the products had pathogenic bacteria contamination and in particular eight of the products showed the presence of all microorganisms analyzed for and they recommended those products should not be used. ${ }^{7}$ These findings need to be noted while recommending these herbal products for the treatment of symptoms of benign prostate hyperplasia.

\section{Traditional Medical Practitioners engaged in the} management of prostate diseases

In Ghana, it is estimated that the ratio of traditional medical practitioners (TMPs) to the population is 1 : $400 .^{35,36}$ This group is a heterogeneous one with different categories of healers. They include bonesetters and herbalists who specialize in the use of herbs and plants, with or without fetish (or spirits) in treating patients. 


\section{Original Article}

It has been observed that each village has its traditional practitioner who uses local plant remedies and in many cases rituals as well, to achieve healing for the population.

The TMPs have been noted to play a very important role in health delivery in the rural areas where there is less access to orthodox facilities with $70-80 \%$ of Ghanaians using traditional medicines. ${ }^{18,19}$ Its importance in Ghana is attributed to the fact that a number of Ghanaians believe that some diseases are not curable with orthodox western medicines.

The combination of mystical powers and the herbs is believed to offer a more lasting solution or cure for some of these diseases. Formal training in the use of traditional herbal medicines has been institutionalized in some of the tertiary institutions in Ghana. These graduates have also set up various 'scientific' herbal clinics that are apparently using more standardized remedies in their traditional medicine practice. This group has been noted not only to manage the primary health care diseases but also tertiary care ones such as hypertension, diabetes mellitus and prostate diseases.

Another category of practitioners are those who have undergone formal orthodox medical training who have veered into the practice of traditional medicine. These operate a hybrid practice with a combination of both orthodox medical care with the requisite supporting investigations and the use of traditional medicinal remedies. However, their practice has been called into question due to their empirical use of these traditional medicines to treat prostate diseases without differentiating between benign and malignant prostate diseases with the management objective being mainly for symptom relief.

\section{Regulation}

To safe guard the health of the Ghanaian population, laws have been enacted to establish regulatory bodies to help ensure proper practice of alternate medicine. The regulatory bodies thus established include the Foods and Drugs Board, the Traditional Medicine Practice Council and the CPMR. The Ghana Medical and Dental Council may need to play a regulatory role in the current hybrid system and the process of integration of alternate medicine into the mainline orthodox medical services.

The mandate of these regulatory Bodies is to ensure a rational use of herbal and plant medicines that are of proven efficacy and safe and to achieve an overall ethical herbal medical practice. The history of the process of recognizing and formalizing traditional remedies in Ghana dates back to 1961 with the formation of the Ghana Psychic and Traditional Healing Association, the establishment of the Centre for Scientific Research into Plant Medicine in 1975, the institution of the Directorate of Herbal Medicine in the Ministry of Health in 1991 and in 1997 the setting up of the Food and Drug Board under the Food and Drugs Law of 1992 (PNDC Law 305b) to regulate and control the commercialization of food and drug products (including traditional medicinal products). A Traditional Medicine Practice Act, Act 575 (Feb. 2000) has been enacted to give legal backing to the regulatory process.

There is the need to streamline the activities of these regulatory bodies to fall in line with current trends and evolution of alternate medical practice particularly in this era of proliferation of mass media outlets offering unsubstantiated claims of efficacy and safety of some herbal products.

\section{Current practice in the use of Traditional Medicines for the treatment of prostate diseases}

The current traditional medical practice in the treatment of prostate diseases does not differentiate between prostatitis, benign prostate hyperplasia and prostate cancer with the herbal remedies being advocated for symptomatic relief in all these conditions.

A prevalence of prostate cancer of about $7 \%$ in the Ghanaian population ${ }^{2,3}$ raises the possible risk of overlooking a prostate cancer if no attempt is made to undertake further investigations that will allow the diagnosis of prostate cancer when present and also provide appropriate and effective treatment.

The optimal management of BPH is equally important because if not managed appropriately complications such as haematuria, renal insufficiency from obstructive uropathy, and recurrent urinary tract infections leading to urosepsis may ensue which could be life threatening. The use of the traditional medicines for the management of prostate diseases among orthodox medical practitioners has been minimal as they are observed with suspicion. The recent observational clinical study on the use of $C$. membranaceus in patients with lower urinary symptoms due to $\mathrm{BPH}{ }^{10}$ should pave the way for a larger study (enrolling more patients) that will help define the patient population that will benefit most, and thus allow for a more targeted use of the product. The efficacy of the product in such a large study as judged by its effect on the international prostate symptoms score (IPSS) [mild, moderate and severe], the quality of life score, the peak flow rate, and the post void urine volume, will help identify the category of patients that will benefit the most. 


\section{Original Article}

To the best of our knowledge, no clinical study has been performed on the use of $C$. membranaceus for prostate cancer treatment. There is therefore the need to clinically differentiate $\mathrm{BPH}$ and prostate cancer to allow for targeted management.

The blanket use of this medication and others to treat prostate diseases including prostate cancer has the potential to lead to under treatment of an underlying prostate cancer that may result in a potential threat to life.

\section{Future research requirements}

As stated earlier, clinical research needs to be conducted to determine the efficacy of C. membranaceus on various prostate diseases to allow for a more targeted treatment. This will also assist in the evaluation of the efficacy of these traditional medicines compared to the more conventional orthodox medications. Further safety studies need also be conducted on C. membranaceus.

As reduction in PSA has been noted with the use of $C$. membranaceus, effect on fertility need to be ascertained especially as it is administered for lower urinary symptoms without any consideration of age and future fertility aspirations. Also of interest is possible interaction of these traditional medicines with other medications. This is of importance as the integration of these traditional medicines into the routine management of prostate diseases is now in effect.

\section{CONCLUSION}

There are both animal and human studies to support the effectiveness of $C$. membranaceus in the management of some patients with lower urinary symptoms due to $\mathrm{BPH}$. What remains to be elucidated is the population subgroup with lower urinary tract symptoms due to BPH in whom C. membranaceus will achieve satisfactory results with respect to good urine flow rates and acceptable post void residual urine volume levels. This will require a large study population to establish. While its medicinal significance has generated scientific interest in the plant there is real concern in relation to the longer-term availability of this indigenous plant in its natural habitat.

The clinical effectiveness of C. membranaceus for the management of prostate cancer has not been established. There is therefore the need to carry out further studies to validate its use among traditional medical practitioners in Ghana in managing all prostate diseases including prostate cancer. Until this is done, efforts must be made to educate users of this plant product of the fact that symptoms of prostate cancer and BPH are often indistinguishable. Every effort must therefore be made at initial evaluation to ensure that those with possible un- derlying prostate cancer are referred for appropriate diagnosis, staging and treatment.

\section{ACKNOWLEDGEMENT}

We acknowledge the staff of the CPMR Ghana for their support in helping identify some of the products and providing access to documentations on their findings.

\section{REFERENCES}

1. Chokkalingam AP, Yeboah ED, Demarzo A, Netto G, Yu K, Biritwum RB, Tettey Y, Adjei A, Jadallah S, li Y, Chu LW, Chia D, niwa S, partin A, Thompson IM, Roehrborn C, Hoover RN, Hsing Aw. Prevalence of BPH and lower urinary tract symptoms in West Africans. Prosate Cancer Prostic Dis. Jun; 15(2):170-6. Doi: 10.1038/pcan.2011.43. Epub 2011 sep 13.

2. Yeboah E., Hsing E, Tetteh Y, Biritwum R, Adjei A, Klufio G, Gepi Attee S, Kyei M, Mensah J, Morton B, Ankomah R, Bentsi I, Quist P, Gyasi R, Akosa A. Prostate Cancer Screening In Ghana. Urology 2009; 74(4) Suppl 1:S200-S201.

3. Hsing AW, Yeboah E, Biritwum R, Tettey Y, De Marzo AM, Adjei A, Netto GJ, Yu K4,Li Y, Chokkalingam AP, Chu LW, Chia D, Partin A, Thompson IM, Quraishi SM, Niwa S, Tarone R, Hoover RN. High prevalence of screen detected prostate cancer in West Africans: implications for racial disparity of prostate cancer. J Urol. 2014 Sep;192(3):730-5. doi: 10.1016/j.juro.2014.04.017. Epub 2014 Apr 18.

4. Kyei MY, Mensah JE, Morton B, Gepi-Attee S, Klufio G.O, Yeboah E.D. Surgical management of BPH in Ghana: a need to improve access to transurethral resection of the prostate. East African Medical Journal 2012; 89 (8):25-29.

5. Kyei MY, Mensah JE, Gepi-Attee S, Kwami D, Ampadu K, Asante E, Klufio GO, Yeboah E.D. Outcomes after Radical Prostatectomy in Ghana: A Surgeons early experience. ISRN Urology Volume 2013 (2013), Article ID 832496, 5 pages http://dx.doi.org/10.1155/2013/832496

6. Yeboah ED, Hsing AW, Biritwum RB, Tettey Y, Mante S, Mensah JE, Kyei MY, Yarney J, Vanderpuije V, Beechem K, Asante K, Ampadu K, Adusei B, GepiAttee S, Klufio GO, Lamptey E, Owoo C, Marzo A, Netto G, Yu K, Li V, Chokkalingham A, Chia D, Jaddalah S, Partin A, Thompson IM, Quaraishi SM, Addo-Ayensu G, Niwa S, Tarone R, Hoover R.N. .Prostate Cancer (Pc)Management Of 669 Cases In Ghana West Africa. Afr J Urol 2014; 20(2):113-114. DOI: 10.1016/j.afju.2014.03.011 


\section{Original Article}

7. Ampofo JA, Andoh A, Tetteh W, Bello M. Microbiological Profile of Some Ghanaian Herbal Preparations-Safety Issues and Implications for the Health Professions. Open Journal of Medical Microbiology. 2012; 2:121-130.

8. Gyasi RM, Mensah CM, Siaw LP. Predictors of traditional medicines utilization in the Ghanaian HealthCare Practice: Interrogating the Ashanti Situation. Journal of community Health. 2015; 40 (2):314-325.

9. Izzo A, Ernst E, "Interactions between Herbal Medicines and Prescribed Drugs: An Updated Systematic Review," Drugs. 2009; 69 (13):1777-1798. doi:10.2165/11317010-000000000-00000

10. Asare GA, Afriyie D, Ngala RA, Appiah AA, Anang Y,Musah I, and Adjei S, Bamfo-Quaicoe K, Sule D, Gyan BA, Arhin P, Edoh DA. Shrinkage of Prostate and Improved Quality of Life: Management of BPH Patients with Croton membranaceusEthanolic Root Extract. Evidence-Based Complementary and Alternative Medicine, Volume 2015 (2015), Article ID 365205, 10 pageshttp://dx.doi.org/10.1155/2015/365205

11. Thompson IM. Pharmacologic agents in complementary medicine in prostatic disease. Drugs Today 2001;37:427-433.

12. Arora RP, Nayak RL, Malhotra V, Mohanty NK. Role of herbal drugs in the management of benign prostatic hyperplasia: Clinical trial to evaluate the efficacy and safety of Himplasia. Med. Update 2003; 11:55-58.

13. Furnharm, "Why Do People Choose and Use Complementary Therapies?" In: E. Ernst, Ed., Complementary Medicine an Objective Appraisal, Butterworth-Heine- mann, Oxford, 1996, p. 170.

14. Ernst E, White A. "The BBC Survey of Complementary Medicine Use in the UK," Complementary Therapies in Medicine. 2000; 8(2000):32-36.

15. Farnsworth NR, Akerele O, Bingel AS, Soejart DD, Guo ZG. "Medicinal Plants in Therapy," Bulletion of the World Health Organization. 1985; 63(6):965981.

16. Eisenberg DM, Davis RB, Ettner SL. "Trends in Alternative Medicine Use in the United States, 1990- 1997-Results of a Follow-Up National Survey," Journal of the American Medical Directors Association. 1998; 280(18):1569-1575. doi:10.1001/jama.280.18.1569

17. World Health Organization, "Traditional Medicine," 2007. http://www.who.int/mediacentre/factsheets/fs134/e $\underline{\mathrm{n} /}$

18. Tabi MM, Powell M, Hodnicki D. "Use of Traditional Healers and Modern Medicine in Ghana," In- ternational Nursing Review. 2006; 53(1):52-58. doi:10.1111/j.1466-7657.2006.00444.x

19. Abel C, Busia K, An Exploratory Ethnobotanical Study of the Practice of Herbal Medicine by the Akan Peoples of Ghana Alternative Medicine Review. 2005; 10 (2):112-122.

20. WHO, The WHO Traditional Medicine Programme: Policy and Implementation, International Traditional Medicine Newsletter. 1985; 1 (1):1-5.

21. http://www.unep-wcmc org/species/plants/ghana.htm)

22. Yevutsey S, Heymann B, Arhin P, Nazzar K. Rapid Assessment of the Pilot Phase of Integration of Herbal and Orthodox Medical practices in selected facilities.http://www.moh.gov.gh/wpcontent/uploads/2016/02/2012

23. Aboagye FA. The effect of Croton membranaceus on dihydrotestosterone levels in blood and its synthesis by prostatic 5 alpha-reductase in the rat [M.Phil. thesis], Department of Biochemistry, University of Ghana, 1997

24. Aboagye FA, Sam GH, Massiot G, Lavaud C, Julocrotine, a glutarimide alkaloid from Croton membranaceus, Fitoterapia. 2000; 71(4):461-462.

25. Bayor MT, Ayim JSK, Marston G, Phillips RM, Shnyder SD, Wheelhouse RT, Wright CW. A cytotoxic diterpenoid from Croton membranaceus, the major constituent of anticancer herbal formulations used in Ghana, Natural Product Communications. 2008; 3(11):1875-1878.

26. Appiah AA, Phytochemical and biological analysis of Croton membranaceus [Ph.D. thesis], Chemistry Department, University of Ghana, 2011

27. Bayor MT, Johnson R, Gbedema SY. The oral capsule-the most appropriate dosage form for croton membranaceus. IJPSR 2011; 2(1):55-62.

28. Afriyie DK, Asare GA, K. Bugyei K, Adjei S, Lin J, Peng J, Hong Z. Treatment of benign. prostatic hyperplasia with Croton membranaceus in an experimental animal model, Journal of Ethnopharmacology. 2014; 157:90-98.

29. Afriyie DK, Asare GA, Bugyei K, Lin J, Peng J, Hong Z, Mitochondria-dependent apoptogenic activity of aqueous root extract of Croton membranaceus against human BPH-1 cells, Genetics and Molecular Research. 2015; 14(1):149-162.

30. Asare' GA, Sittie A, Bugyei K, Gyan BA, Adjei S, Addo P, Wiredu EK, Nyarko AK, Otu-Nyarko LS, Adjei DN. Acute toxicity studies of Croton membranaceus root extract. Journal of Ethnopharmacology. 2011; 134:(3):938-943.

31. Afriyie DK, Asare GA, Bugyei K, Asiedu-Gyekye I, Gyan BA, Adjei S, Addo P, Sittie A, Nyarko AK. Anti-atherogenic and anti-ischemic potentials of Croton membranaceus observed during sub-chronic 
toxicity studies. Pharmacognosy Research. 2013; 5(1): 10 .

32. Appiah AA. Phytochemical and biological analysis of Croton membranaceus [Ph.D. thesis], Chemistry Department, University of Ghana, 2011

33. Appiah AA, Asomaning WA, Oppong IV, DukerEshun G, Clement J, Okine LKN, Achel G, Gyampo O, Adjei S, Nyarko AK, Aboagye FA, Edoh DA. African Natural Plant Products Volume II: Discoveries and Challenges in Chemistry, Health, and Nutrition. 2013; chap 6, Volume 1127 page 7992. DOI: 10.1021/bk-2013-1127.ch006

34. Sittie AA, Quality Assessment. In a Manual of Harmonized Procedures for Assessing the Safety,
Efficacy and Quality of Plant Medicines in Ghana, Yamens Press Ltd., Accra, 2005

35. STEPRI (2007) Ghana Herbal Pharmacopoeia, Science and Technology Policy Research Institute (STEPRI), Accra

36. Antwi-Baffour SS, Bello AI, Adjei DN, Mahmood SA, Ayeh-Kumi PF. The place of traditional medicine in the African society: The science, acceptance and support. American Journal of Health Research. 2014; 2(2):49-54. 